\title{
Design of a System for Monitoring Technology Multiple Application in Order to Measure the Gap in Technology Companies "MiPymes"
}

\author{
Álvaro Espinel Ortega, Víctor Martín García and Adriana Marcela Vega Escobar \\ Computer Science Department, Pontifical University of Salamanca, Madrid, Spain
}

\begin{abstract}
This is one of several articles that aims to disseminate the research results in developing advanced doctoral paper entitled: Model of System for Technological Surveillance for multiple application to measure the technological gap in Colombian companies.

This paper is related to the design of Technological Surveillance, following the Rational Unified Process for software development, commonly known as RUP® [1], UML® [2] and

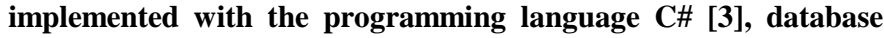
engine SQL Server, set to an architectural model of three (3) layers (3-Tier). This document takes into account especially related to requirements, architecture and modeling and subsequent articles are related to testing, evaluation and results of the prototype was implemented and results in the field of technologically surveillance exercises, all in accordance with the objectives of the Doctoral Paper.
\end{abstract}

Keywords - Bibliometrics, Competitive intelligence, Data mining, Metasearch engines, patents, Scientometrics, Technological Surveillance, Technology roadmaps.

\section{INTRODUCTION}

$\mathrm{C}$ Oolombian companies are oriented either to the production of goods or services, especially those classified as micro, small and medium enterprises, usually called by the acronym "MiPymes" do not have friendly computational tools for monitoring processes to different aspects related to technological advances, which have to do with its production facilities, which is why many of these companies currently have obsolete technologies or do not use any of them. A question arises?. If the technology is and has been the key for countries to position themselves at the head of economic development, because they also observed by the use of technological advances in different fields that make up to use the knowledge gained to benefit those who need, ie companies and especially those that make up the vast majority who have no resources for undertaking this type of research, such as the "MiPymes". "MiPymes" mean "Micro, Pequeñas y Medianas Empresas" in Spanish. In English micro, small and médium enterprise.

\section{PROBLEM}

This raises the second question. How much is the difference or gap between Colombian companies and their counterparts in developed countries?. It is possible to measure the gap? and similarly raises other questions such as: The gap in technology is just as it has always wanted to see? Or it may be related to methodologies? Or with the knowledge that people have that make the company? This is a complex problem that must be addressed comprehensively and in a first phase that would allow making diagnosis of the current situation of Colombian companies to establish or at least propose state policies which address those areas that laggards are to become competitive.

\section{A. Formulation of the Problem}

It is possible to design and implement a surveillance system of multiple applications, to measure the technology gap, based on indicators of different types, configurable and manageable, so that as a result of this process is to propose strategies or policies for improving processes in Colombian businesses and / or discover new areas that make the country more competitive?

\section{OBJECTIVES}

\section{A. General Objective}

Show the processes used for designing a model surveillance system technology to measure the technology gap between Colombian companies and similar businesses elsewhere. This is to show some of the results of a doctoral paper and for the benefit of entrepreneurs who want to improve their competitiveness.

\section{B. Specific Objectives}

Perform modeling and design a system to manage information for "MiPymes" to process the basic data related to their sector or workplace.

Perform design and modeling of a document management system, which allows searches of documents related to innovation like patents and scientific articles in order to classify and catalog, to get them relevant information associated with technological surveillance.

Perform design and modeling of a system of indicators, associated with human resources, technological indicators, 
indicators on innovation and economic and financial indicators.

Implement a prototype system to measure the digital divide so that comparisons can be made at the company level, in terms of chains, links, sectors and economic activities.

\section{SURVEILLANCE TECHNOLOGY CONCEPTS}

"Technology Watch is an organized process, selective and permanent, to capture information from abroad and the organization of science and technology to select, analyze, disseminate and communicate it to turn it into knowledge to make decisions with less risk and be able to anticipate the changes. "Definition according to UNE 166006:2006. [4]. Spain.

All this in an atmosphere of legality, that the difference of espionage.

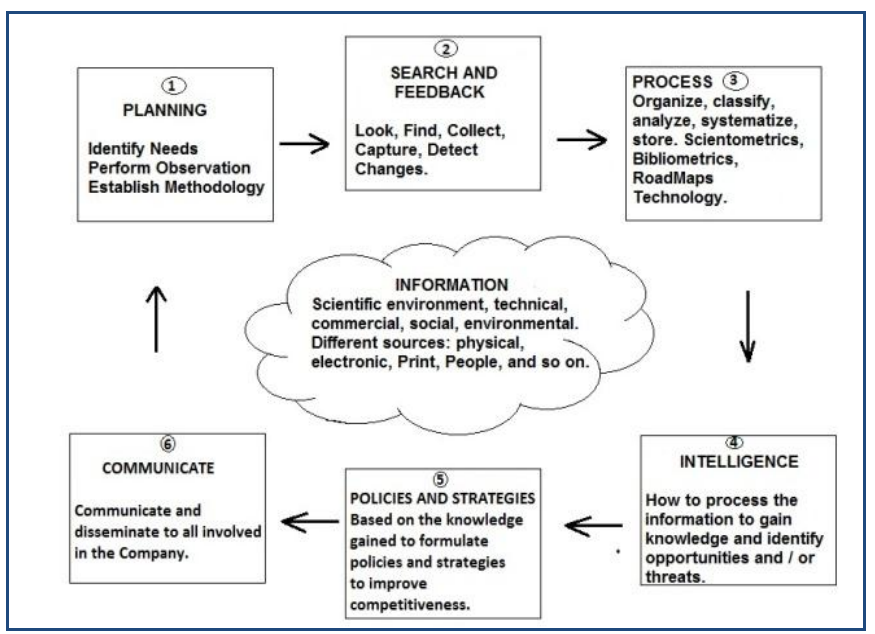

Figure 1. The cycle of technological surveillance.

The purpose of surveillance technology can be considered the following:

Anticipate: To detect the changes: new technology, machines, markets, competitors, internal, external.

Reducing Risk: Detect threats: Patents, products, regulations, alliances, new investments.

Progressing: Improve cost benefit.

Innovate: Improve the quality, performance, new ideas, new solutions.

Cooperate: Contribute to improving the environment.

Compete: Have permanence and excel in the market.

Fields of application: Develop strategies to establish R \& D programs, to establish cooperation agreements to facilitate the implementation of new technological developments, identify opportunities for investment and marketing.

Sources of Information: We have formal and informal. In the case of formal sources are: scientific databases (eg, Scopus $®$, Compendex $₫$, Chemical Abstracts $₫$, SCI $®$, SSCI $®)$, patent databases (Eg WIPO $®$, WPI $®$, EPAT $®$, CIBEPAT $®)$, scientific journals. In the case of informal information sources: public Internet, trade magazines, fairs, Invisible Web.

\section{A. Competitiveness}

The best indicator of the competitiveness of a country's per capita income of its inhabitants. "The competitiveness of a nation is its ability to produce goods and services in international markets, maintaining or increasing real incomes of its citizens. Competitiveness is the basis of standard of living of a country. "OECD. (Organization for Economic Cooperation and Development). [5]

\section{B. What Issues Should Watch}

According to Michael Porter of Harvard University. [6], among others should monitor technological, competitive and commercial environment.

\section{1) Technological aspects}

It should monitor progress of science and technology, the result of basic and applied research, products and services, manufacturing processes, materials, their processing chain, technology and information systems. [7]

\section{2) Competitive aspects}

Analysis and monitoring of current and potential competitors.

\section{3) Commercial aspects}

Markets, customers, the evolution of their needs, their solvency, suppliers, its strategy of launching new products, the labor force in the industry and value chain

\section{4) Aspects of environment}

The laws and regulations, culture, people, non-tariff barriers, free trade, environment, etc.

\section{Technology Watch and Competitive Intelligence}

The word competitive intelligence tends to replace the term technological surveillance at establishing a more active character, presents a more elaborate and better prepared for decision-making. Between the two disciplines is a slight difference, while surveillance technology puts the emphasis on seeking and obtaining relevant information for decision making, competitive intelligence refers to the same process but with the emphasis on the development of this information often involves the obtaining of new information to really understand. [7]. 


\section{V.DESIGN PROCESS STEPS}

\section{A. Phase I: Conceptual Review.}

We conducted a conceptual review process on the theoretical foundation for technological monitoring systems, taking national and international benchmarks in Europe and the United States and the international sector taking as reference points include the Organization for Economic Cooperation and Development (OECD) [5] World Trade Organization, World Economic Forum, the European Community and later other regions such as Asia and emerging countries of Latin America. Were taken into account also the Oslo Manual [8] and Frascti Manual [9].

We performed a process review of experiences in the field of technological surveillance nationally and internationally to learn about the sources of information valid for information extraction processes at the level of scientific articles, patents and documents related to innovation technology, such as databases indexed and the mechanisms used by those who have completed this process. Among others was a comprehensive review of the standards UNE 166000, 166001.166002, 166003, 166004. [10].

\section{B. Phase II: Selection and classification of indicators and sources of information valid as the basis for the technology gap.}

It should set up a different kind, which are necessary to classify, catalog and rank in the social, economic, technical and scientific in accordance with international benchmarks. The indicators provide the basis for setting the gap based on the proposed monitoring system. You must also choose valid sources of information, based on selected indicators and taking into account international references in order to establish the requirements for the automated search systems, using "metasearch", which receive information parameterized by the systems plans to design and implement. For this case we used a metasearch engine called Copernic Agent $\AA$, with its accessories COPERNIC TRACKER $®$ and Copernic Summarizer ${ }^{\circledR}[11]$.

\section{Phase III: Development of Model for Technological Surveillance System proposed.}

Based on the requirements established in previous phases, will proceed with the construction of UML ${ }^{\circledR}$ models [2], following the RUP $₫$ [1] known as the Unified Process of Software Development.

\section{Phase IV: Implementation of a Functional Prototype.}

Working prototype was implemented with a database in SQL Server $®$, Visual Studio development tool NET $®$. The prototype includes some exercises with Colombian companies properly classified according to the international codification of economic activities ISIC $\AA$, in order to validate the model. This prototype is being tested in collaboration with the Economic Development Secretariat of Bogotá and some businessmen from different sectors.

\section{E. Phase V: Testing, Prototype Evaluation And Publication Of Results.}

The final results of the testing and evaluation of the prototype are scheduled for publication in later articles, as indicated in the summary of this document.

\section{SURVEILLANCE SYSTEM DESIGN TECHNOLOGY}

\section{A. Requirements.}

Functional requirements are the needs of users viewed from the perspective of software and generally relate below: Requirements for Business Management "MiPymes" documentary requirements, requirements for indicators, monitoring requirements on technological requirements on technology gap measure, requirements for system users

\section{B. Requirements Specification}

In the final design document requirements are specified using the following guidelines: Specified in writing, with opportunities to test or verify, based on the needs of current and potential users of the information system and described with a feature of the system develop as clearly and concisely as possible in order to avoid misinterpretation. The same analysis was performed based on individual formats based on scenarios.

\section{Requirements as Expression of Use Cases}

After analyzing the requirements are documented as case proceeded to use the software in a format that considers: Use case name, Actors, entry conditions, processes, output and flow conditions alternate.

In summary use cases to observe a general view seen below:

1) Use Cases user management subsystem

System users are four types: Entrepreneur, Expert in the area Technology Watch, Coordinator of Surveillance Technology and System Administrator, who are defined by these profiles and user roles.

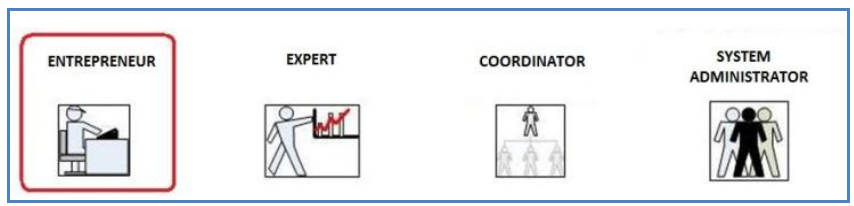

Figure 2. System Users and Roles

- Manage user roles: user Create Role, Change user role, user role See, Delete user role.

- Manage Users: Create User, Edit User, Delete User, Browse User.

2) Use cases document management subsystem

Manage processes with scientific papers (Scientometrics, Bibliometrics for scientific databases), manage patent documents processes (search for information on patent 
databases), document management tools for technological maps (Road-Map).

\section{3) Subsystem use case management indicators}

Manage types of indicators Qualitative indicators, manage domain of qualitative, quantitative, quantitative indicators to manage scale, manage categories of indicators, indicators on human resources management, management training indicators, management indicators employment, manage Research and Innovation indicators, manage patent indicators, management indicators on $\mathrm{R} \& \mathrm{D}$, Innovation indicators managing companies, managing technological indicators, output indicators, indicators, production processes, process indicators, service level indicators, process innovation, innovation indicators for customer relations, indicators of organizational innovation, global innovation indicators, indicators on new concepts, new product management indicators, management indicators redefinition of production processes, manage indicators redefining marketing processes indicators to business model innovation, manage economic and financial indicators.

\section{4) Measurement subsystem use case gap}

Determine or manage technological gap, seek information are automatically respective subsystems, creating technological surveillance study, upload information manually, assign responsible for the study, surveillance study technological change, seeking technological surveillance study, see technological surveillance study to determine gap, generate technological surveillance study report, graphical reporting on technological surveillance study.

\section{5) Subsystem information on "MiPymes"}

Managing Information "MiPymes", create, modify, consult codes, refer to by name, delete data "MiPymes" manage economic activity, manage supply chains, manage location, manage link in the chain.

6) Chaos overview of the system use

According the above analysis and after performing a process of cohesion, Technology Surveillance System consists of the following subsystems: management "MiPymes" User Management Subsystem (the main plot is omitted) management subsystem documentary Subsystem Indicators, Measurement Subsystem Technology Gap.

\section{Use Case Diagrams}

Diagrams are shown modeled General - Private (Top-Down), ie the general view showing first and then the detail.
1) Use case diagram overview of the surveillance system technology

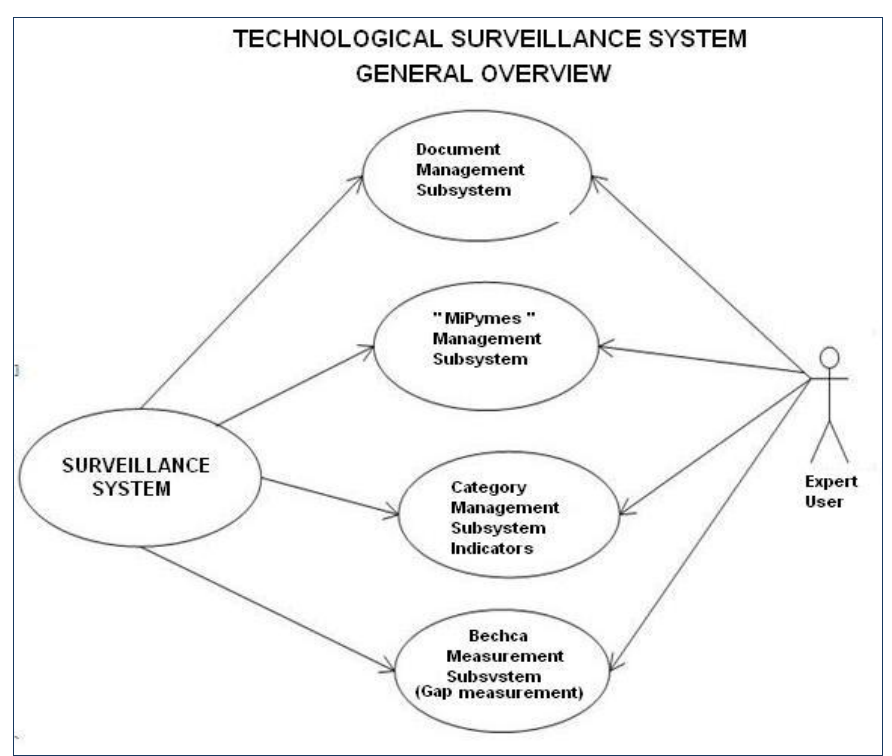

Figure 3. General Diagram view Use Case TS System

2) General diagram view detailed system use cases overview of the surveillance system technology

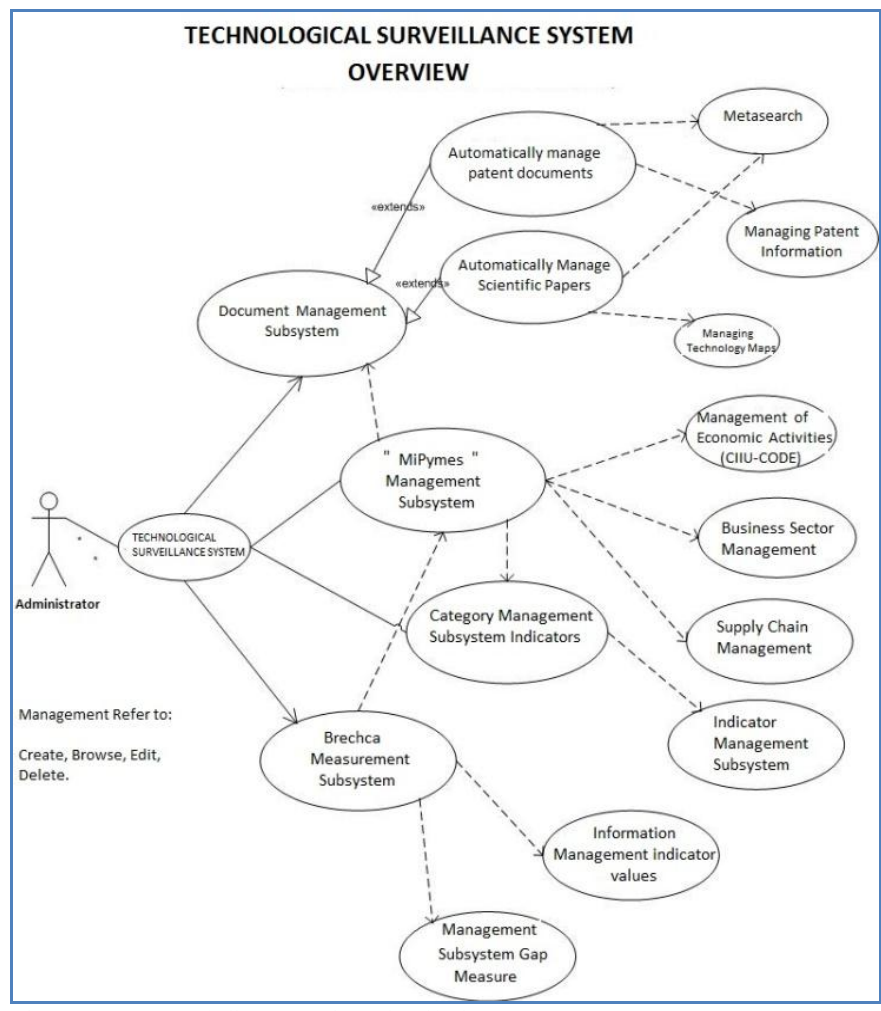

Figure 4. General diagram view detailed system use cases.

3) Use case diagrams managing "MiPymes" 


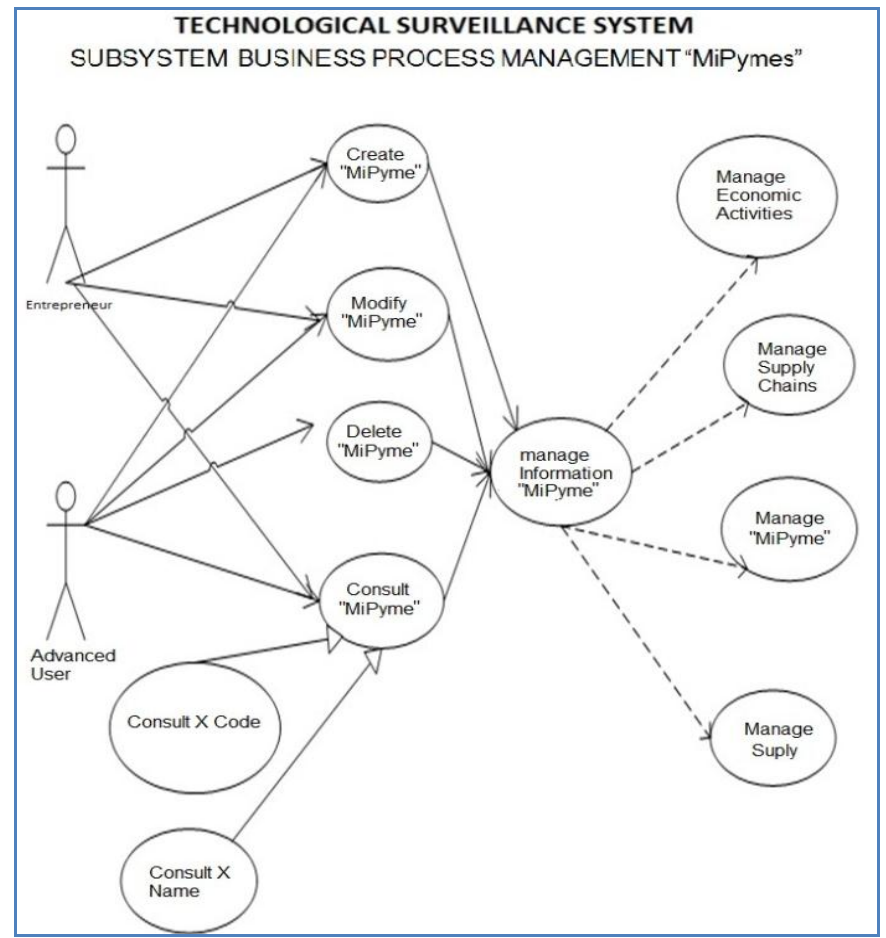

Figure 5. Use case diagrams. Managing "MiPymes"

4) Use case diagrams Managing indicators.

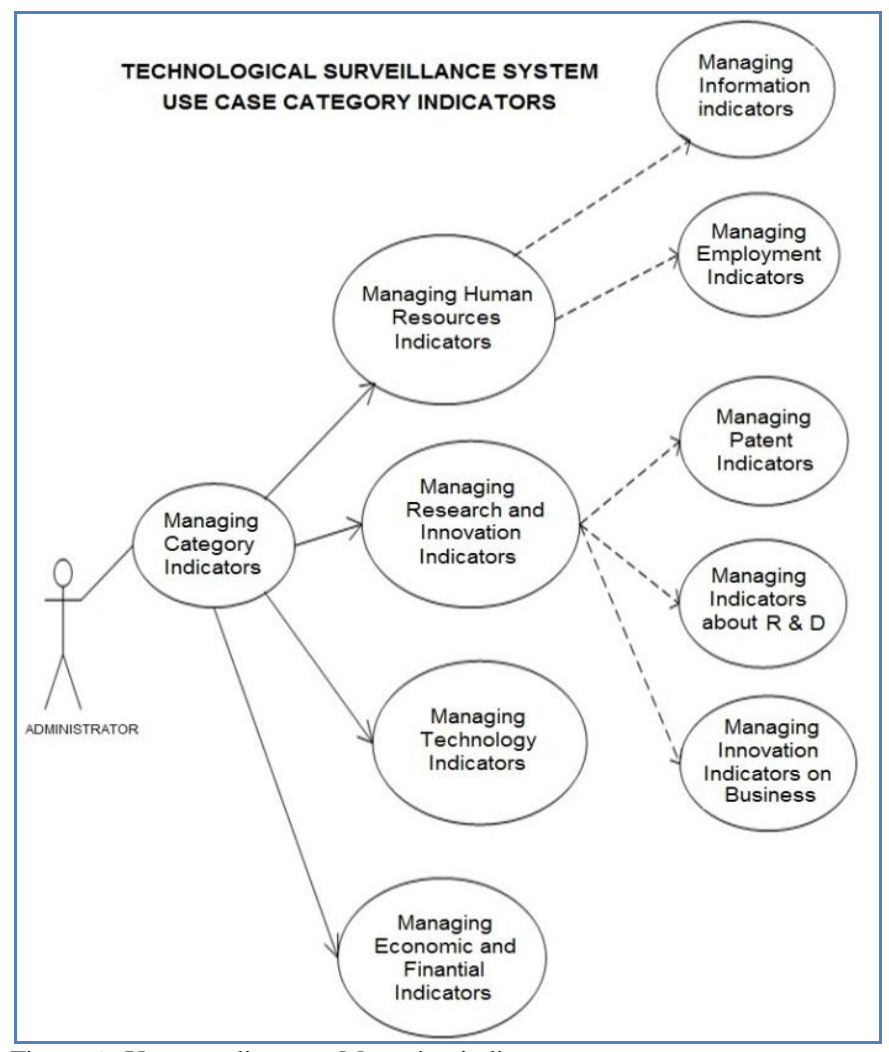

Figure 6. Use case diagrams Managing indicators.

5) Use case diagram Measuring technology gap

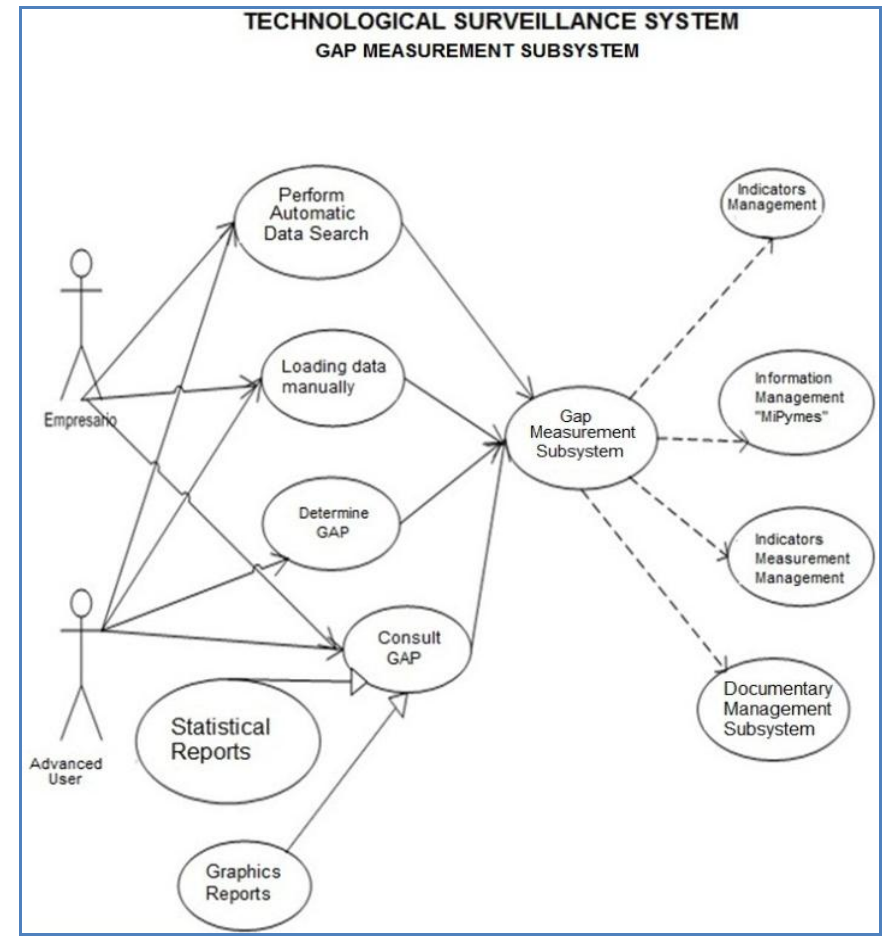

Figure 7. Use case diagrams. Measuring technology gap

\section{E. Class Diagram}

It shows a class diagram of the surveillance system technology by way of illustration we have chosen the related Management "MiPymes"

\section{1) Class Diagram Managing "MiPymes"}

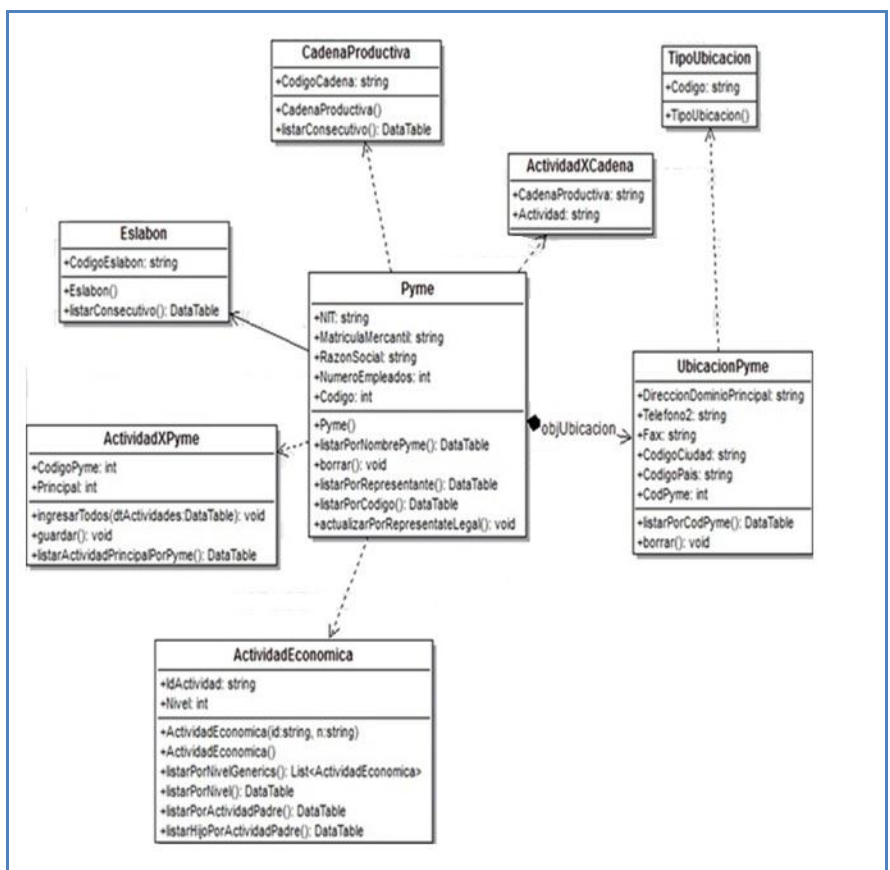

Figure 8. Class Diagram Managing "MiPymes" 


\section{F. Packages diagram Technological Surveillance System}

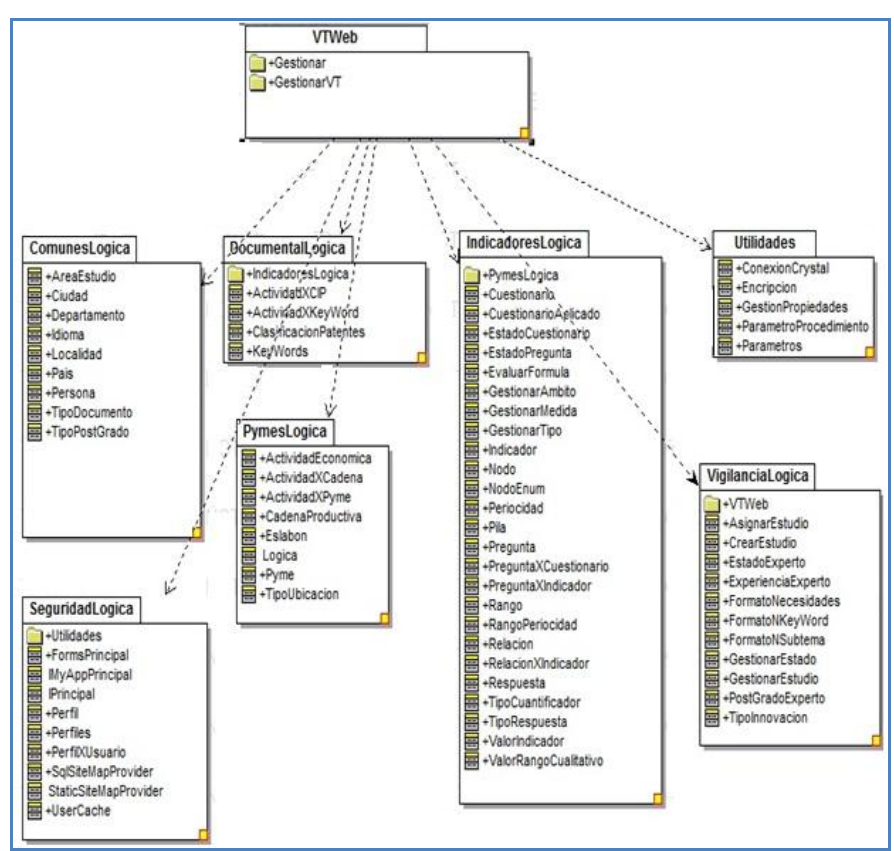

Figure 9. Packages diagram Technological Surveillance System

\section{G. Deployment diagram showing the components of the Technological Surveillance.}

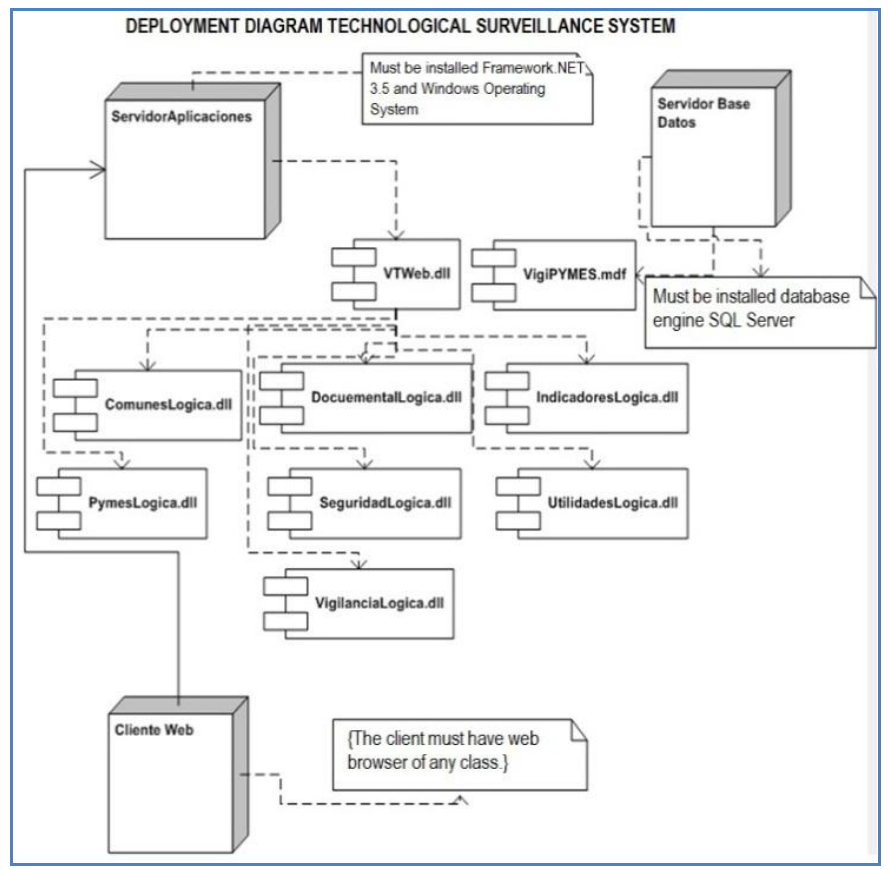

Figure 10. Deployment diagram showing the components of the TS System

VII. SYSTEM COMMISSIONING AND FIRST TESTS RESUlTS.

The system has been installed and put into service on a server of the Ministry of Economic Development, Bogotá DC, and the exercises have been conducted demonstration, of which you can see the following screen shot.

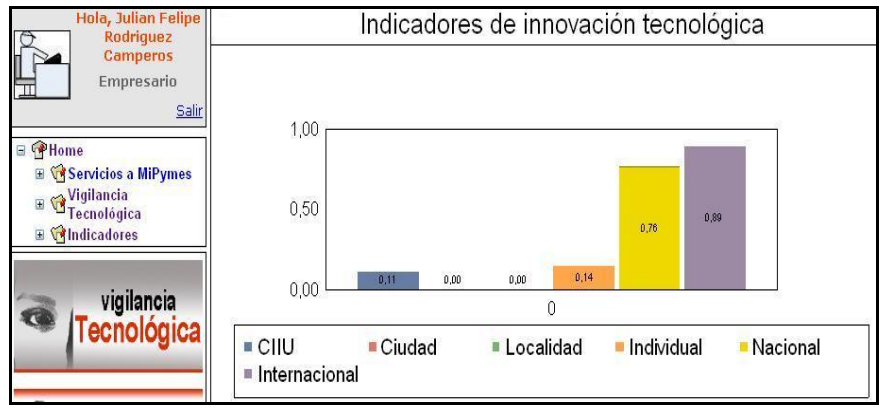

Figure 11. Report with results of Technological Innovation Indicators

Both entrepreneurs and experts and coordinator (s) Technological Surveillance System have the ability to view the indicators, special forms have been configured to make comparisons between different areas of the indicators.

The system has a configuration to store historical data and therefore generate display options indicators.

The system administrator has the option to export the historical data of the scenario indicators formats that allow the system to do data processing.

\section{VIII.CONCLUSIONS}

These findings relate to the design process and implementation of the system and the possibilities it can have the system in national and international context. The analysis of results on measurement exercises will the gap in subsequent publications, for which to date has fifty surveys Entrepreneurs Bogotá D, C, in the Republic of Colombia.

Are known as the country's businesses, companies face a similar character in the international context, by selecting a set of indicators based on international benchmarks, to measure the technology gap, allows decisions to establish policies on the part of employers and state policies to reduce this gap and increase business competitiveness through better use of human and financial resources.

With an observation of this kind, performed computational tools based on the Colombian state and the businessmen may have some references, to propose policies to support those sectors that are in crisis, discover new areas potentially important to support and discard those who lost their validity.

This tool can be potentially useful for multiple applications, it can be configured so that it applies to any kind of company, whether of goods or services, regardless of the economic activity performed and production chains to which they belong.

This tool not only to measure technological gap, but conforms to the observation and measurement of different aspects given the ability to configure and establish hierarchies in the indicators. These indicators can be set as qualitative or quantitative case in which you can set the range and scale of possible values that can take.

There are no state policies in Colombia, regarding technological surveillance exercise or at least observation in the fields of science, technology and innovation that will 
improve their production processes, which is why this tool can be a good reference upon making the process of testing and evaluation in the Ministry of Economic Development of Bogotá D, C, where there are already several surveys about to process the results will be subjected to analysis.

Technological surveillance studies in the vast majority focus on purely technological aspects that ignore methodological aspects and human resources that the system here designed is able to cover.

Micro, small and medium enterprises in most Latin American countries regardless of their economic activity, do not use or have tools for monitoring processes to different aspects of technological advances and innovation, they have to do with the improving their knowledge, processes, procedures and equipment, which is why they are at a competitive disadvantage compared to similar companies in developed countries.

This research was a first step to promote small and medium entrepreneurs in Colombia, the importance of observation on various technological aspects involved in the production processes of their companies, in order to improve competitiveness.

Have been generated as a result of this investigation a number of documents and an application that can be very useful for entrepreneurs so they can be used from their companies.

\section{REFERENCIAS}

[1] BOOCH Graddy, RUMBAUGH James, JACOBSON Ivar. AddisonWesley . El Proceso Unificado de Desarrollo de Software. Rational Unified Process-RUP®, Addison-Wesley. Pearson. 2003

[2] BOOCH Graddy, RUMBAUGH James, JACOBSON Ivar. El Lenugaje Unificado de Modelado - UML®. Segunda Edición Addison-Wesley. Pearson. 2005.

[3] ECMA-334. Lenguaje de Programación Orientado a Objetos C\#. Standard ECMA-334 C\# Language Specification.

Disponible en:

http://www.ecma-international.org/publications/standards/Ecma334.htm

[4] AENOR. UNE 166006:2006 Título en español: Gestión de la I+D+i: Sistema de Vigilancia Tecnológica. Consultado: Octubre-2010.

Disponible en:

http://www.aenor.es/aenor/normas/normas/fichanorma.asp?codigo=N00 36140\&tipo=N

[5] OCDE. Organización para la Cooperación y el Desarrollo Económico. Consultado: Nov-2010.

Disponible en:

http://www.oecd.org/pages/0,3417,es_36288966_36288120_1_1_1_1_ 1,00.html

[6] PORTER Michael E., padre de la estrategia competitiva.Portal MateriaBiz. Consultado: Nov-2010.

Disponible en: http://www.materiabiz.com/mbz/gurues.vsp?nid=22600

[7] ESCORSA, Pere; MASPONS, Ramón. De la Vigilancia Tecnológica a la Inteligencia Competitiva. Madrid: Prentice Hall, 2001.

[8] OCDE. MANUAL DE OSLO. Guía para la recogida e interpretación de datos sobre innovación.

http://www.conacyt.gob.sv/Indicadores\%20Sector\%20Academcio/Manu al_de_Oslo\%2005.pdf

Consultado: Octubre de 2009

El texto completo de esta obra se encuentra en: http://www.sourceocde.org/9264013113

[9] OCDE. MANUAL DE FRASCATI. "Medición de las Actividades Científicas y Tecnológicas" .

http://www.edutecne.utn.edu.ar/ocde/frascati-01.htm Consultado: Octubre de 2009

[10] AENOR. UNE 166000, 166001,166002, 166003, 166004. Normas relacionadas con I+D. Consultado: Octubre-2010.

Disponible en:

http://www.aenor.es/aenor/normas/buscadornormas/buscadornormas.asp ?modob $=\mathrm{S}$

[11] COPERNIC SOFTWARE INC. COPERNIC AGENT®, con sus $\begin{array}{llll}\text { complementos COPERNIC TRACKER } & \text { Y } & \text { COPERNIC }\end{array}$ SUMMARIZER®.

Consultado: Enero 2010

Disponible en:

http://www.copernic.com/index.html 